Tuberc Respir Dis 2012;73:331-335

Copyright(C)2012. The Korean Academy of Tuberculosis and Respiratory Diseases. All rights reserved.

\title{
A Case of Invasive Thymoma with Endotracheal Polypoid Growth
}

Jin Tae Hwang, M.D. ${ }^{1}$, Min Hee Kim, M.D. ${ }^{1}$, Ki Jun Chang, M.D. ${ }^{1}$, Hyo Jeong Chang, M.D. ${ }^{1}$, Soo Jeon Choi, M.D. ${ }^{1}$, Young Jin Yuh, M.D. ${ }^{1}$, Jung Yeon Kim, M.D. ${ }^{2}$, Hye Kyeong Park, M.D. ${ }^{3}$

Departments of ${ }^{1}$ Medicine and ${ }^{2}$ Pathology, Inje University Sanggye Paik Hospital, Inje University College of Medicine, Seoul,

${ }^{3}$ Department of Medicine, Inje University Ilsan Paik Hospital, Inje University College of Medicine, Goyang, Korea

Thymomas are one of the most common neoplasms of the mediastinum derived from thymic epithelium. It is common that invasive thymoma invades the lung, pericardium, and great vessels. Airway compression by mass effect also occurs, but direct polypoid tumor growth into the airway is extremely rare. Only 20 cases of invasive thymoma with endobronchial polypoid growth have previously been reported globally. However, there is no case report of invasive thymoma with endotracheal growth. Herein, we report a rare case of invasive thymoma with endotracheal polypoid growth in a 28 -year-old woman.

Key Words: Thymoma; Bronchoscopy

\section{Introduction}

Thymoma is the most common primary tumor of the anterior mediastinum. Most thymomas are completely surrounded by a fibrous capsule. However, 34\%, regardless of size, may invade through the capsule and extend directly into the adjacent organs. Because invasive thymomas lack histological features of malignancy, the term "invasive thymoma" is preferred over "malignant thymoma" ${ }^{1}$. Although invasive thymoma, which progresses locally at times, applies pressure to the trachea, there has been no report yet of its invasion of trachea through the proliferation of polypoid tumors. Up to the present, however, there have been 20 cases all over the world of invasive thymoma with endobronchial polypoid growth ${ }^{2-4}$. The authors have experienced

Address for correspondence: Soo Jeon Choi, M.D.

Division of Respirology, Departments of Medicine, Sanggye

Paik Hospital, 1342, Dongil-ro, Nowon-gu, Seoul 139-707, Korea

Phone: 82-2-950-8838, Fax: 82-2-3392-1013

E-mail: choisj@paik.ac.kr

Received: May 8, 2012

Revised: May 17, 2012

Accepted: Jun. 11, 2012

(a) It is identical to the Creative Commons Attribution Non-Commercial License (http://creativecommons. org/licenses/by-nc/3.0/). a case of invasive thymoma with endotracheal polypoid growth and have successfully treated it. This case is reported here along with a literature review.

\section{Case Report}

A 26-year-old female patient had dyspnea three weeks ago, and underwent a chest computed tomography (CT) scan at the emergency unit of other hospital. A mediastinal tumor that had invaded the trachea was discovered, and the patient was referred to our hospital. The patient had a history of thyroidectomy six years ago, but there was nothing significant to report in her family history. She did not drink alcohol or smoke. Her blood pressure at the time of hospital visit was 115/65 $\mathrm{mm} \mathrm{Hg}$, with pulse rate of 100 beats/min, a respiration rate of 24 breaths/min, and a body temperature of $37.0^{\circ} \mathrm{C}$. According to the physical findings, she was acutely sick, but was alert, and the conjunctiva of both eyes and lips were not pale. There were neither facial, cervical swelling and nor jugular vein ectasia. Stridor was audible in both upper lung fields and heart sound was normal. Her abdomen was flat, bowel sound was normal, and no tenderness or rebound tenderness was observed in her abdomen. She had no hepatosple- 


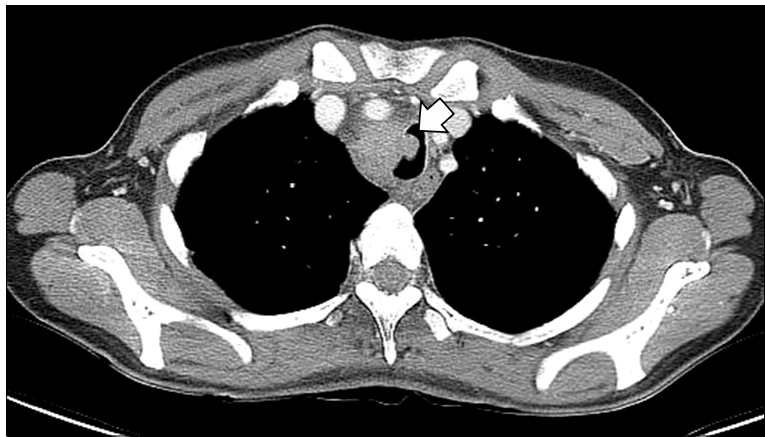

Figure 1. Chest computed tomography showed about $3.3 \times 2.4 \mathrm{~cm}$ sized homogenous enhancing mass in the right paratracheal area with tracheal stenosis and polypoid growth into the airway tract.

nomegaly and no lump. According to the laboratory findings, her hemoglobin count was $13.1 \mathrm{~g} / \mathrm{dL}$; white blood cell count, $11,820 / \mathrm{mm}^{3}$ (77.4\% neutrophils, $12.7 \%$ lymphocytes, and $0.9 \%$ eosinophils); platelet count, 249,000/ $\mathrm{mm}^{3}$; and C-reactive protein, $1.2 \mathrm{~mL} / \mathrm{dL}$. In the arterial blood gas analysis that was performed immediately before the hospital visit, the $\mathrm{pH}$ was 7.404; $\mathrm{PCO}_{2}, 38.7 \mathrm{~mm} \mathrm{Hg} ; \mathrm{PO}_{2}, 52.9 \mathrm{~mm} \mathrm{Hg} ; \mathrm{HCO}_{3}, 23.7$ $\mathrm{mEq} / \mathrm{L}$; and $\mathrm{SaO}_{2}, 87.7 \%$. According to the biochemical analysis, the total serum protein was $7.0 \mathrm{~g} / \mathrm{dL}$; albumin, $3.9 \mathrm{~g} / \mathrm{dL}$; aspartate aminotransferase, $14 \mathrm{IU} / \mathrm{L}$; alanine aminotransferase, $3 \mathrm{IU} / \mathrm{L}$; blood urea nitrogen, $6 \mathrm{mg} / \mathrm{dL}$; creatinine, $0.6 \mathrm{mg} / \mathrm{dL}$; and lactate dehydrogenase, 347 $\mathrm{U} / \mathrm{L}$. On the chest X-ray image, volume reduction of the right upper lobe and tracheal deviation to the right were observed, and a lump was suspected on the right wall of the trachea. The superior mediastinum on the chest CT scan (performed in other hospital) showed tracheal stenosis and invasion of a uniform mass with a relatively clear boundary that measured approximately $3.3 \mathrm{~cm}$ (Figure 1).

On the second day of the patient's hospitalization, bronchoscopy was performed, and tracheal stenosis accompanied by a polypoid tracheal tumor that was blocking the lumen in the middle of the tracheal tube was observed (Figure 2). An endoscopic tissue biopsy was performed, and the result of the tissue test showed chronic inflammation that included fibrin exudation. On

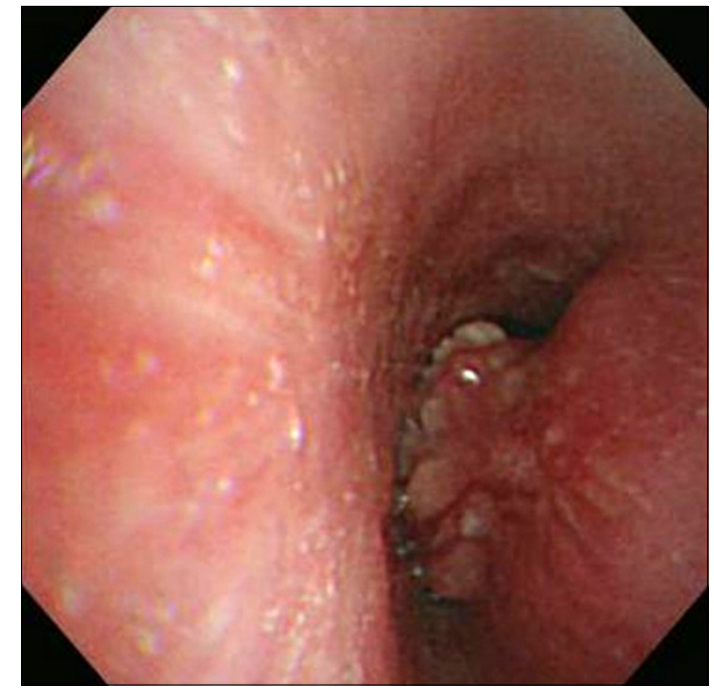

Figure 2. Bronchoscopic examination showed a polypoid tumor in the mid-trachea with obstruction of the tracheal lumen.

the third day of the patient's hospitalization, fiberoptic bronchoscopy was performed again for the histological diagnosis, but only chronic inflammation with granulation tissue was observed. A definite diagnosis cannot be confirmed from the tissue biopsies that were performed twice, and on the fifth day of the patient's hospitalization to relieve upper airway obstruction and for the histological confirmation, tracheal tumor resection and end to end anastomosis were performed at the Department of Thoracic Surgery at our hospital. The final post-operative tissue findings showed type B3 thymoma of the World Health Organization (WHO) classification which appeared to have intruded up to the subepithelial region of the trachea (Figures 3 5).

After the surgery, the patient's symptoms improved; and a month after the surgery, four cycles of adjuvant chemotherapy were carried out with a combination of cyclophosphamide $\left(500 \mathrm{mg} / \mathrm{m}^{2}\right)$, doxorubicin $\left(50 \mathrm{mg} / \mathrm{m}^{2}\right)$, and cisplantin $\left(50 \mathrm{mg} / \mathrm{m}^{2}\right)$. A relapse of the cancer was found in the operation site on the chest CT scan six months after the surgery, and the patient underwent radiotherapy with a total radiation level of 7,200 cGy for eight weeks. The patient is now under outpatient follow-up with complete remission since September 2010. 


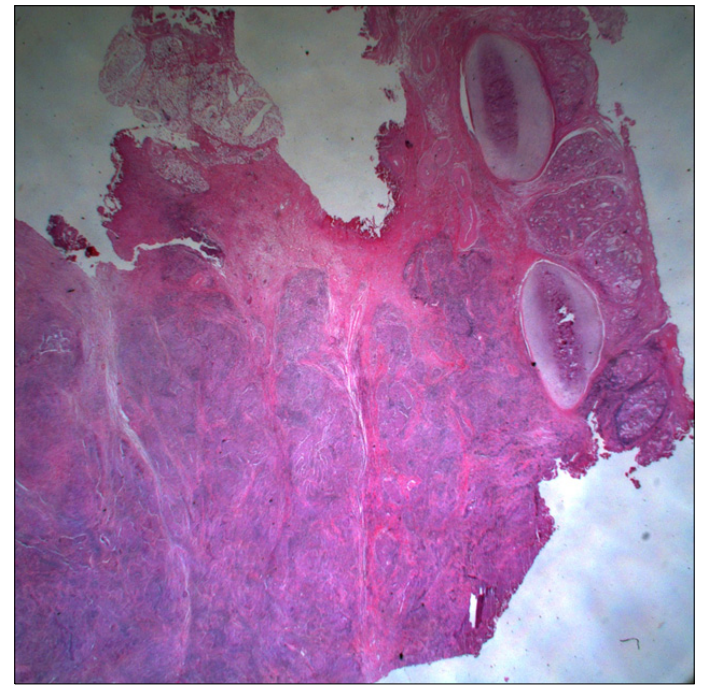

Figure 3. The tumor showed focal extension beyond tracheal cartilage to the tracheal subepithelial stroma (H\&E stain, $\times 10)$.

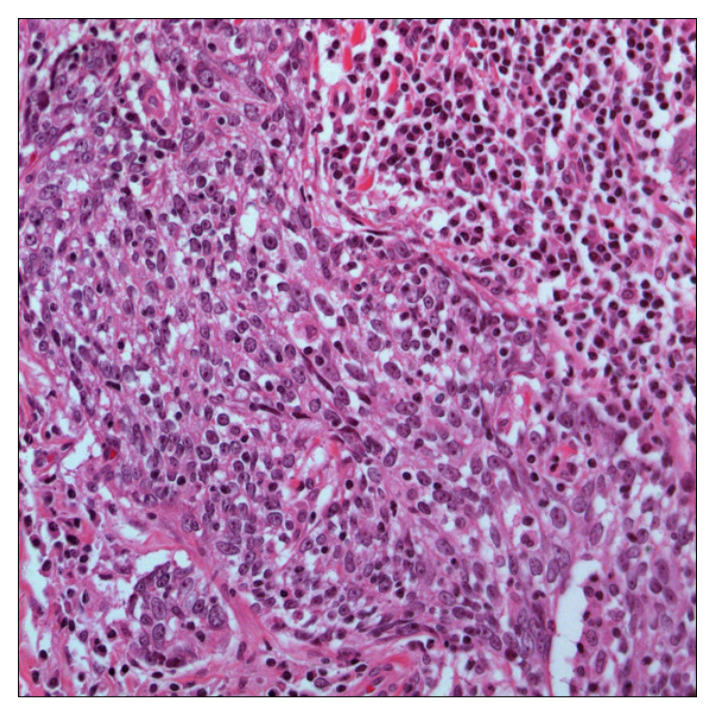

Figure 4. Biopsy revealed proliferation of the epithelial cells with some mitotic figures. They are admixed a mild component of lymphocyte (H\&E stain, $\times 400)$.

\section{Discussion}

Thymoma is the most common primary tumor of the anterior mediastinum. Most patients are asymptomatic, although one third experience chest pain, cough, dyspnea, and other symptoms related to compression or invasion of adjacent structures. Up to one half of patients

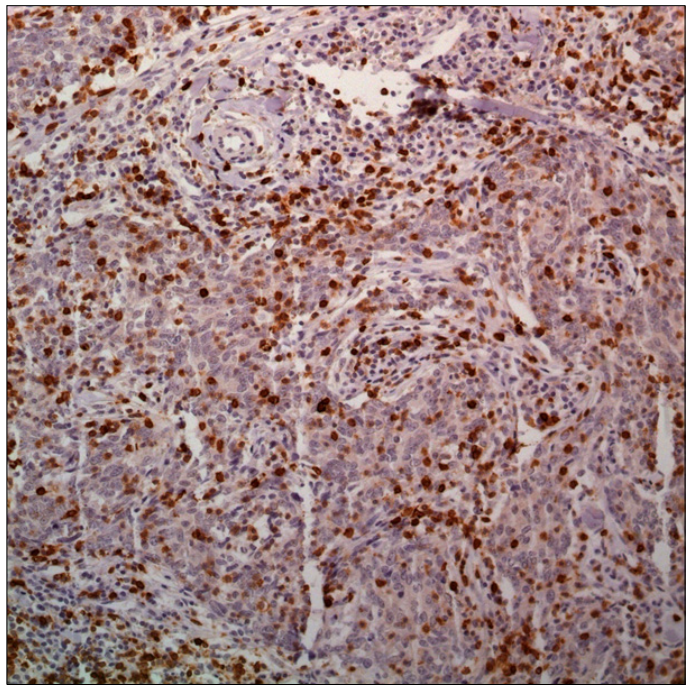

Figure 5. The tumor cells showed positive immunoreactivity for CD5 $(\times 400)$.

suffer from one or more parathymic syndromes, most commonly myasthenia gravis, hypogammaglobulinemia, and pure red cell aplasia ${ }^{1}$. Pathologically, the thymus is a complex organ with epithelial and lymphoid elements and represents the main site of T-cell maturation, and thymoma is a neoplasm derived from thymic epithelium ${ }^{5}$. Thymic carcinoma is distinguished from thymoma from the point that it shows atypia, mitosis, and cellular necrosis, and is usually not accompanied by myasthenia. Type B3 thymoma of the WHO classification seen in this case had features that were similar to those of thymoma, while showing cellular dysplasia or mitosis $(<2$ per 10 high power field), and often showed myasthenia gravis and other parathymic conditions ${ }^{1,6}$.

The surgical excision is mainstay of the treatment of thymoma, and whether or not surgical excision was performed has a significant impact on the prognosis. Patients with unresectable invasive thymoma are treated with radiotherapy or systemic chemotherapy ${ }^{7}$. The survival rate of patients with type B3 thymoma varies by reports, the 5-year overall survival rates are known to be $60 \sim 80 \%$ ( $75 \%$ on the average), and majority ( $73 \%$; range, $58 \sim 83 \%$ ) of patients are found to have Masaoka stage III or IV $\mathrm{V}^{6,8}$. While two thirds of patients with type 
B3 thymoma can undergo complete surgical excision, the effect of radiotherapy or chemotherapy in this group is not well-known ${ }^{6}$. This case fits on Masaoka stage III, in which there is a local invasion of the trachea. For its treatment, adjuvant chemotherapy was performed with a combination of cyclophosphamide, doxorubicin, and cisplantin after complete surgical excision. Eventhough the tumor recurred six months later, complete remission could be achieved by radiotherapy.

Up to the present, according to a literature review, there has been a total of 20 reported cases wherein invasive thymoma had shown endobronchial polypoid tumor growth. Nineteen of these 20 patients had shown symptoms of shortness of breath, and one patient had no symptom. The mass directly infiltrated or appeared through hematogenous or lymphangitic metastasis, and there were more invasions in the left bronchial tree than in the right ${ }^{2-4}$. However, there have been no case reports of invasive thymoma that showed polypoid proliferation by infiltrating only the trachea without invading the lung or blood vessels, as seen in this case.

A tissue confirmation by bronchoscopy before surgery is rare among cases of invasive thymoma with endobronchial polypoid growth. Normal bronchial mucosa or sphacelus has been observed as a result of biopsy using bronchoscopy in a majority of cases, except for two cases reported by Asamura et al. ${ }^{2}$ and a case reported by Sakuraba et al. ${ }^{3}$. Even in this case, tissue biopsies were tried twice with bronchoscopy, but it was difficult to make a definite diagnosis, and a histological confirmation was possible only after the surgical resection. Biopsies were unsuccessful due to unstable respiration rate and hypoxemia. As a result, we could not obtain adequate amounts of tumor tissue in the tracheal subepithelial areas invaded by the thymoma. The biopsied specimens obtained by bronchoscopy only contained tracheal epithelium and granulation tissue, and not thymus-like epithelial cells.

An immunohistochemical study of the biopsy specimen would have been helpful in making a diagnosis. Epithelial cells are positive for cytokeratin (CK) 19, CK5/6, CK7, CK10, and CK8, while immature T-cells are positive for CD1a, CD4, CD8, CD5, CD99, and $\mathrm{TdT}^{9}$. Our biopsy specimens obtained by surgical resection showed positive immunoreactivity for pan-CK and CD5 (Figure 5). These findings support the histological features for a thymoma characterized by an admixture of epithelial cells and lymphocytes.

The mechanism of the tracheal or bronchial mass proliferation of invasive thymoma is not yet clearly known. Honda et al. ${ }^{10}$ presumed that thymoma first invades the parietal pleura or visceral pleura, and then infiltrates the lung and the distal bronchial wall, after which it progresses to endobronchial polypoid proliferation. In the case of this patient, the trachea was invaded by the tumor directly.

In case of the existence of an endotracheal tumor, a differential diagnosis would have to consider fibroma, hemangioma, papilloma, or squamous cell carcinoma among primary tumors, and to consider lung cancer, esophageal cancer, mediastinal tumor, head and neck tumor, or lymphoma as a secondary tumor ${ }^{11}$. Although this is rare, the fact that thymoma, among mediastinal tumors, can progress to polypoid proliferation and take on the appearance of an endotracheal tumor. Furthermore, since there are still only a few of these cases and because treatment of type B3 thymoma has not been clearly established yet, it is believed that more case reports and studies are needed.

\section{References}

1. Strollo DC, Rosado de Christenson ML, Jett JR. Primary mediastinal tumors. Part 1: tumors of the anterior mediastinum. Chest 1997;112:511-22.

2. Asamura H, Morinaga S, Shimosato Y, Ono R, Naruke T. Thymoma displaying endobronchial polypoid growth. Chest 1988;94:647-9.

3. Sakuraba M, Sagara Y, Tamura A, Park Z, Hebisawa A, Komatsu H. A case of invasive thymoma with endobronchial growth. Ann Thorac Cardiovasc Surg 2005; 11:114-6.

4. Benton SM Jr, Rogers RP 3rd, Reed CE. Invasive thymoma with endobronchial metastasis. Ann Thorac Surg 2010;89:612-4.

5. Hasserjian RP, Ströbel P, Marx A. Pathology of thymic 
tumors. Semin Thorac Cardiovasc Surg 2005;17:2-11.

6. Detterbeck FC, Parsons AM. Thymic tumors. Ann Thorac Surg 2004;77:1860-9.

7. Duwe BV, Sterman DH, Musani AI. Tumors of the mediastinum. Chest 2005;128:2893-909.

8. Masaoka A, Monden Y, Nakahara K, Tanioka T. Follow-up study of thymomas with special reference to their clinical stages. Cancer 1981;48:2485-92.

9. Travis WD, Brambilla E, Müller-Hermelink HK, Harris CC. World Health Organization classification of tu- mours: pathology and genetics of tumors of the lung, pleura, thymus and heart. Lyon: IARC Press; 2004.

10. Honda T, Hayasaka M, Hachiya T, Hirose Y, Kubo K, Katsuyama $\mathrm{T}$. Invasive thymoma with hypogammaglobulinemia spreading within the bronchial lumen. Respiration 1995;62:294-6.

11. Flint P, Haughey B, Lund VJ, Niparko JK, Richardson MA, Robbins KT, et al. Cummings otolaryngology: head and neck surgery. 5th ed. St. Louis: Mosby, Inc.; 2010. p. 1611-24. 